\title{
Microfluidic Autologous Serum Eye-Drops Preparation as a Potential Dry Eye Treatment
}

\author{
Takao Yasui ${ }^{1,2,3, *}$, Jumpei Morikawa ${ }^{1}$, Noritada Kaji ${ }^{1,2}{ }^{\text {, Manabu Tokeshi }}{ }^{2,4}$, Kazuo Tsubota ${ }^{5}$ \\ and Yoshinobu Baba ${ }^{1,2,6, *}$ \\ 1 Department of Applied Chemistry, Graduate School of Engineering, Nagoya University, Furo-cho, \\ Chikusa-ku, Nagoya 464-8603, Japan; morikawa.jumpei@gmail.com (J.M.); \\ kaji@apchem.nagoya-u.ac.jp (N.K.) \\ 2 ImPACT Research Center for Advanced Nanobiodevices, Nagoya University, Furo-cho, Chikusa-ku, \\ Nagoya 464-8603, Japan; tokeshi@eng.hokudai.ac.jp \\ 3 Japan Science and Technology Agency (JST), PRESTO, 4-1-8 Honcho, Kawaguchi, Saitama 332-0012, Japan \\ 4 Division of Applied Chemistry, Faculty of Engineering, Hokkaido University, Sapporo 060-8628, Japan \\ 5 Department of Ophthalmology, School of Medicine, Keio University, Tokyo 160-8582, Japan; \\ tsubota@z3.keio.jp \\ 6 Health Research Institute, National Institute of Advanced Industrial Science and Technology (AIST), \\ Takamatsu 761-0395, Japan \\ * Correspondence: yasui@apchem.nagoya-u.ac.jp (T.Y.); babaymtt@apchem.nagoya-u.ac.jp (Y.B.); \\ Tel.: +81-52-789-4611 (T.Y.); +81-52-789-4664 (Y.B.); Fax: +81-52-789-4666 (T.Y. \& Y.B.)
}

Academic Editors: Andrew J. deMello and Nam-Trung Nguyen

Received: 27 May 2016; Accepted: 30 June 2016; Published: 4 July 2016

\begin{abstract}
Dry eye is a problem in tearing quality and/or quantity and it afflicts millions of persons worldwide. An autologous serum eye-drop is a good candidate for dry eye treatment; however, the eye-drop preparation procedures take a long time and are relatively troublesome. Here we use spiral microchannels to demonstrate a strategy for the preparation of autologous serum eye-drops, which provide benefits for all dry eye patients; $100 \%$ and $90 \%$ removal efficiencies are achieved for $10 \mu \mathrm{m}$ microbeads and whole human blood cells, respectively. Since our strategy allows researchers to integrate other functional microchannels into one device, such a microfluidic device will be able to offer a new one-step preparation system for autologous serum eye-drops.
\end{abstract}

Keywords: dry eye; autologous serum eye-drops; spiral microchannel

Dry eye is a problem in tearing quality and/or quantity, mainly due to overusing personal computers, tablets, and smartphones, air-drying, and wearing contact lenses. Nowadays, the number of persons suffering from dry eyes may well be over a hundred million worldwide and it increases daily. Dry eyes may be seen as a lack of tears on the corneal epithelial layer induced by corneal damage, and it is also a symptom of problems such as meibomian gland dysfunction and Sjögren's syndrome. Since the reasons for dry eyes are not straightforward, commercially available eye-drops are generally insufficient to treat dry eyes completely; they only can lubricate the front surface of the eye.

Autologous serum eye-drops are a good candidate for dry eye treatment since they contain epidermal growth factor (EGF), vitamin A, and so on, which is essential for cell differentiation and division [1-3]. Treatment using the autologous serum eye-drops is based on the concept that dry eye worsening is not due to drying out the front surface of the eye, but rather to poorly supplying essential components to the cornea; therefore, the autologous serum eye-drops can treat dry eyes comprehensively, by not only lubricating the front surface of the eye but also promoting cornea regrowth by the EGF [4]. Autologous serum eye-drops have two features. One is that users can reduce the chance of infection because the person's own blood is utilized, and the other is that the eye-drops 
can be stored for up to three months at $-80^{\circ} \mathrm{C}$. The autologous serum eye-drops are prepared as follows: first, a patient's blood is collected in a heparin-unmodified blood collection tube; secondly, the collected blood is centrifuged at $3000 \mathrm{rpm}$ for $10 \mathrm{~min}$; thirdly, the supernatant is filtered through a $0.45-\mu \mathrm{m}$-pore-size filter; and finally, the filtered serum is diluted to reach a target concentration using saline. However, the preparation is relatively troublesome and takes a long time due to the centrifugation, filtration, and dilution steps.

Here we demonstrated a strategy for the preparation of autologous serum eye-drops using a microfluidic technique. Microfluidics has shown great promise for significantly improving diagnostics, as well as biological and medical research studies [5]. Microfluidics has been variously used for passive blood cells separation approaches [6], such as hydrodynamic separation [7-17], sedimentation-based separation [18-21], and filtration-based separation [22-33]. Considering the desire for high throughput and the need for a further dilution process, we fabricated a spiral microchannel (Figure 1a) to realize inertial migration, one of the hydrodynamic separation techniques [34]. In curving microchannels, particles experience a combination of inertial lift force and Dean drag force; inertial lift force acts to focus microbeads at an equilibrium position between the channel wall and centerline [35,36], and Dean drag force acts to entrain microbeads as two counter-rotating vortices with flow directed toward the outer bend at the midline of the channel and inwards at the channel edges [37,38]. A ratio of these forces (inertial lift, $F_{L} /$ Dean drag, $F_{D}$ ) would be a key parameter to determining the equilibrium positions of the microbeads $[39,40]$. An inertial force ratio, $R=F_{L} / F_{D} \approx a^{3} \approx 1 / H^{3}$, where $a$ is the particle diameter and $H$ is the channel height, is obtained by dividing the dimensional scaling of the inertial lift force with the scaling of the Dean drag force [13,40,41]. This force ratio shows that particles with a larger diameter migrate to inertial equilibrium positions, and particles in a channel of larger height do not migrate to inertial equilibrium positions but remain entrained in the channel vortices. We demonstrated the focusing of $10-\mu \mathrm{m}$-diameter microbeads $(2.65 \%$, Polyscience, Inc., Warrington, $\mathrm{UK}$ ) at the equilibrium position close to the inner wall of the spiral microchannel (Figure 1b). Using the spiral microchannel, we performed blood cell removal for the microfluidic autologous serum eye-drops preparation as a potential dry eye treatment.

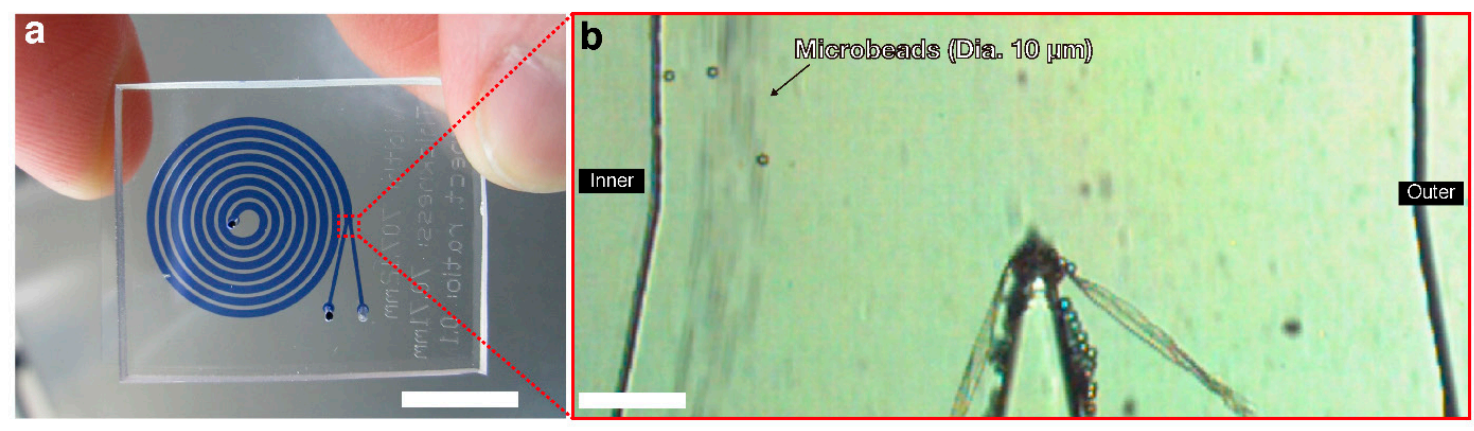

Figure 1. A spiral microfluidic device. (a) Photograph of a spiral microfluidic device; scale bar, $10 \mathrm{~mm}$. Microchannels are highlighted by Trypan blue dye solution. Channel width and height are 707 and $70.7 \mu \mathrm{m}$, respectively. Distance between two adjacent microchannels is $303 \mu \mathrm{m}$; (b) A magnified micrograph of part of a spiral microchannel, enclosed by the red dotted box in Figure 1a; scale bar, $100 \mu \mathrm{m}$. Ten-fold diluted microbeads (10 $\mu \mathrm{m}$ diameter) in phosphate buffered saline were focused at an equilibrium position close to the inner wall of the microchannel.

For the fabrication of microfluidic devices with a spiral microchannel, we used poly(dimethylsiloxane) (PDMS; silpot 184, Dow Corning Toray Co., Ltd., Tokyo, Japan) replication techniques from an SU-8 mold (SU-8 3050, Nippon Kayaku Co., Ltd., Tokyo, Japan). First, photo-curable SU-8 resin was spin-coated on Si substrates (Silicon Technology Co., Ltd., Tokyo, Japan) and pre-baked at $95{ }^{\circ} \mathrm{C}$ for $20 \mathrm{~min}$. The thickness of the SU-8 resin was controlled by spinner rotation speed and time. The SU-8 microchannel was patterned by a mask aligner (MJB4, SÜSS MicroTec AG., Munich, Germany) 
through emulsion photomasks (Topic Co., Ltd., Kawaguchi, Japan). In addition, the patterned SU-8 resin was post-baked at $95^{\circ} \mathrm{C}$ for more than $4 \mathrm{~min}$ and developed using a SU-8 developer (Nippon Kayaku Co., Ltd.). The developed SU-8 mold was finished by putting it into a vacuum chamber under a trichloro $(1 \mathrm{H}, 1 \mathrm{H}, 2 \mathrm{H}, 2 \mathrm{H}$-perfluorooctyl)silane atmosphere for $3 \mathrm{~h}$. PDMS was poured into the silanized SU-8 mold and cured at $80^{\circ} \mathrm{C}$ for $2 \mathrm{~h}$. After peeling off the cured PDMS, via holes were made for one inlet and two outlets. The PDMS with the via holes and glass slides were bonded to each other after plasma treatment (SDP-1012, Meiwafosis Co., Ltd., Tokyo, Japan). Removal efficiency (collection efficiency) was calculated by dividing the number of introduced microbeads or blood cells by collected ones. In addition, the number of microbeads or blood cells was calculated using collected sample volume and concentrations, which are estimated from a calibration curve (optical density vs. concentrations).

The spiral microchannels showed $100 \%$ removal efficiency for $10-\mu \mathrm{m}$-diameter microbeads, which is a model material for blood cells (Figure 2). The features of the spiral microchannels, such as the aspect ratio, the number of microchannel spirals, and flow rates, should be candidate parameters governing removal efficiency. Since maximum channel velocity, which is determined by the cross-sectional area of the microchannel, is known to affect removal efficiency [34,40-42], we supposed that the cross-sectional area should be $50,000 \mu \mathrm{m}^{2}$. By changing the aspect ratio from 0.1 to 1.0 under other fixed conditions, we concluded that the aspect ratio from 0.1 to 0.2 was suitable for $10 \mu \mathrm{m}$ particle removal; in particular, the 0.1 ratio gave a $99 \%$ removal efficiency ( $1 \%$ collection efficiency) at the outer outlet (Figure 2a). This meant that a smaller aspect ratio had higher removal efficiency, which was in good agreement with the behavior predicted by the inertial force ratio: particles in a smaller height channel migrated to inertial equilibrium positions. Next, we considered the effect of the number of microchannel spirals, ranging from 0.5 to 7.5 spirals, on removal efficiency (Figure 2b). Figure $2 \mathrm{c}$ showed that the removal efficiency increased with an increase of the number of microchannel spirals, leading to $99 \%$ removal efficiency ( $1 \%$ collection efficiency) at one outer outlet in 7.5 spirals. From the above results, we used the spiral microchannel with a 0.1 aspect ratio and 7.5 spirals to examine influence of flow rates on removal efficiency (Figure 2d). As we increased the flow rate from 100 to $5000 \mu \mathrm{L} / \mathrm{min}$, the removal efficiency drastically improved, and finally we achieved $100 \%$ removal efficiency $(0 \%$ collection efficiency) at the flow rate of $5000 \mu \mathrm{L} / \mathrm{min}$.

Finally, we introduced whole human blood into the spiral microchannels and achieved $90 \%$ removal efficiency of blood cells at the outer outlet (10\% collection efficiency) (Figure 3). After sampling and centrifugation of whole human blood, we mixed blood cells and blood plasma to be $50 \%$ hematocrit, and then we diluted the blood sample using phosphate buffered saline to reach target hematocrit values. As for the $10 \mu \mathrm{m}$ microbeads, the removal efficiency of blood cells increased as the flow rate increased; however, we could not attain $100 \%$ efficiency due to the disc shape of the red blood cells which had an $8 \mu \mathrm{m}$ diameter and $2.5 \mu \mathrm{m}$ thickness (Figure 3a). Considering the inertial force ratio, it made sense that removal efficiency was degraded for the smaller particle diameter. It is well known that the inertial lift force drops with a decrease in the Reynolds number [34-36], and as we expected, the viscosity of the blood samples affected removal efficiency, and the removal efficiency at the outer outlet increased to $90 \%$ (10\% collection efficiency) as the concentration decreased (Figure 3b). Figure 3c shows photographs of collected blood samples at the inner and outer outlets; hemolyzed blood was not observed. We confirmed that hemolyzed blood was not observed at any of the concentrations used (Figure 3b). From these results, we concluded that inertial force in the spiral microchannels at the concentrations used had no hemolyzing property. 

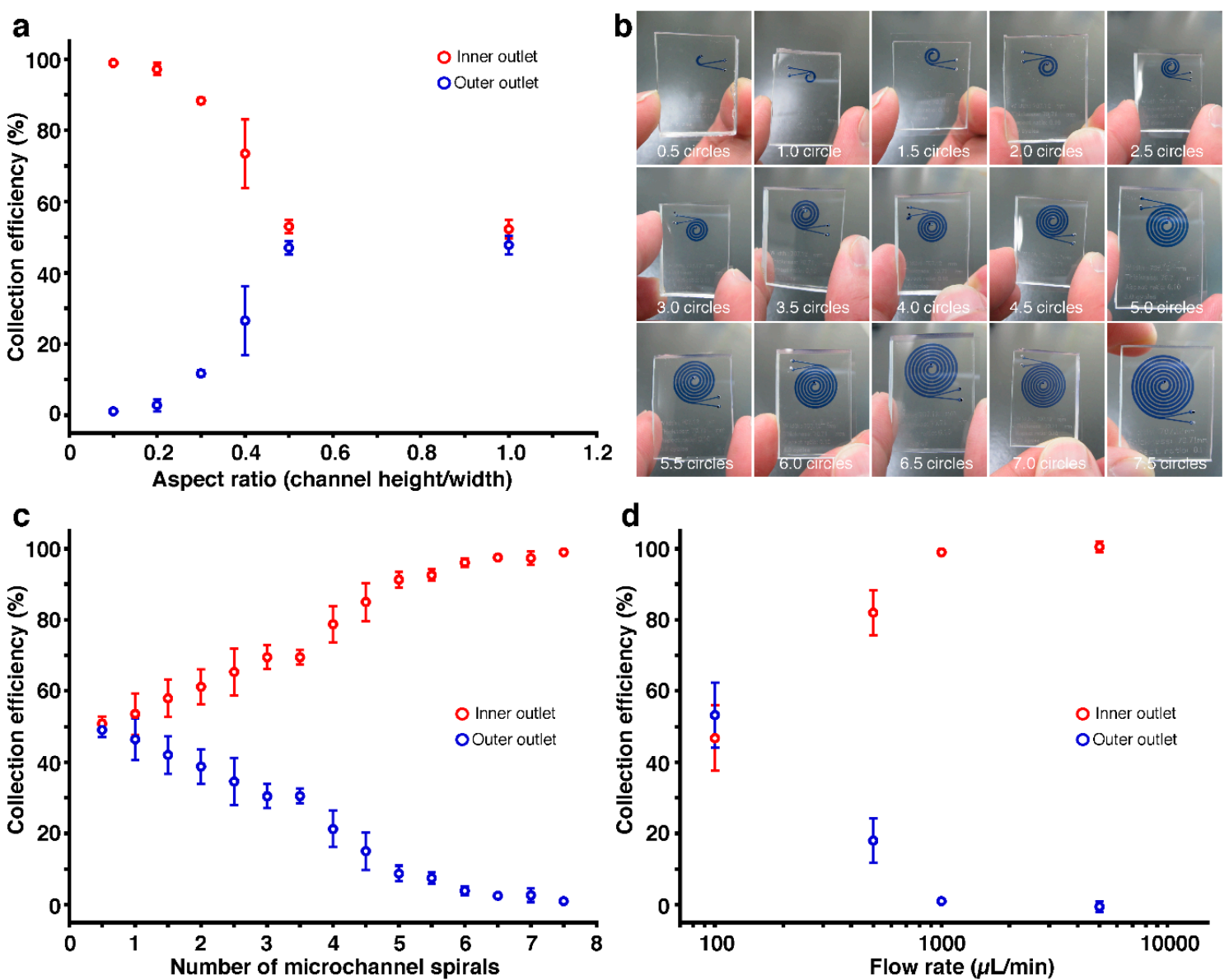

Figure 2. Collection efficiency of $10 \mu \mathrm{m}$ particles. Cross-sectional area was 50,000 $\mu \mathrm{m}^{2}$. Ten-fold diluted microbeads (10 $\mu \mathrm{m}$ diameter) in phosphate buffered saline were used. Error bars are the standard deviation for a series of measurements $(N=3)$. (a) Collection efficiency vs. aspect ratio of spiral microchannels. The aspect ratio is the ratio of channel height to width. The number of microchannel spirals was 7.5, and flow rate was $1000 \mu \mathrm{L} / \mathrm{min}$; (b) Photographs of fabricated spiral microchannels with 0.5 to 7.5 circles. One circle is one spiral. The microchannels are highlighted by Trypan blue dye solution; (c) Collection efficiency vs. number of microchannel spirals. The aspect ratio of the microchannels was 0.1 , and flow rate was $1000 \mu \mathrm{L} / \mathrm{min}$; (d) Collection efficiency vs. flow rate. The aspect ratio of the microchannels was 0.1 , and the number of microchannel spirals was 7.5 .

To achieve the $100 \%$ removal efficiency of blood cells, we can propose two methods: increasing the inertial lift force and decreasing the Dean drag force. Both ways lead to increasing the inertial force ratio. For increasing the inertial lift force, we should increase the Reynolds number by increasing the flow rates $[36,43,44]$. In this approach, we could apply $10,000 \mu \mathrm{L} / \mathrm{min}$ for a maximum flow rate due to a deformability issue of PDMS. Since $\mathrm{Si}$, glass or polymethyl methacrylate (PMMA) are much harder materials than PDMS, these microchannels can be good candidates for applying more than $10,000 \mu \mathrm{L} / \mathrm{min}$. Note that we should confirm the hemolysis issue of blood cells when we apply more than $10,000 \mu \mathrm{L} / \mathrm{min}$. For decreasing the Dean drag force, we should decrease the Dean number by reducing the channel height or increasing the curvature ratio [38-40]. In this approach, we used the microchannels with a 0.1 aspect ratio and 7.5 spirals due to a roof collapse issue of PDMS and a size issue of glass slides. Si, glass or polymethyl methacrylate (PMMA) microchannels would also help researchers to avoid the roof collapse issue and reduce the aspect ratio, and a larger size of the glass slides would allow researchers to avoid the size issue and increase the number of microchannel spirals. Note that we should confirm a clogging issue of blood cells when we use lower aspect ratio microchannels. 

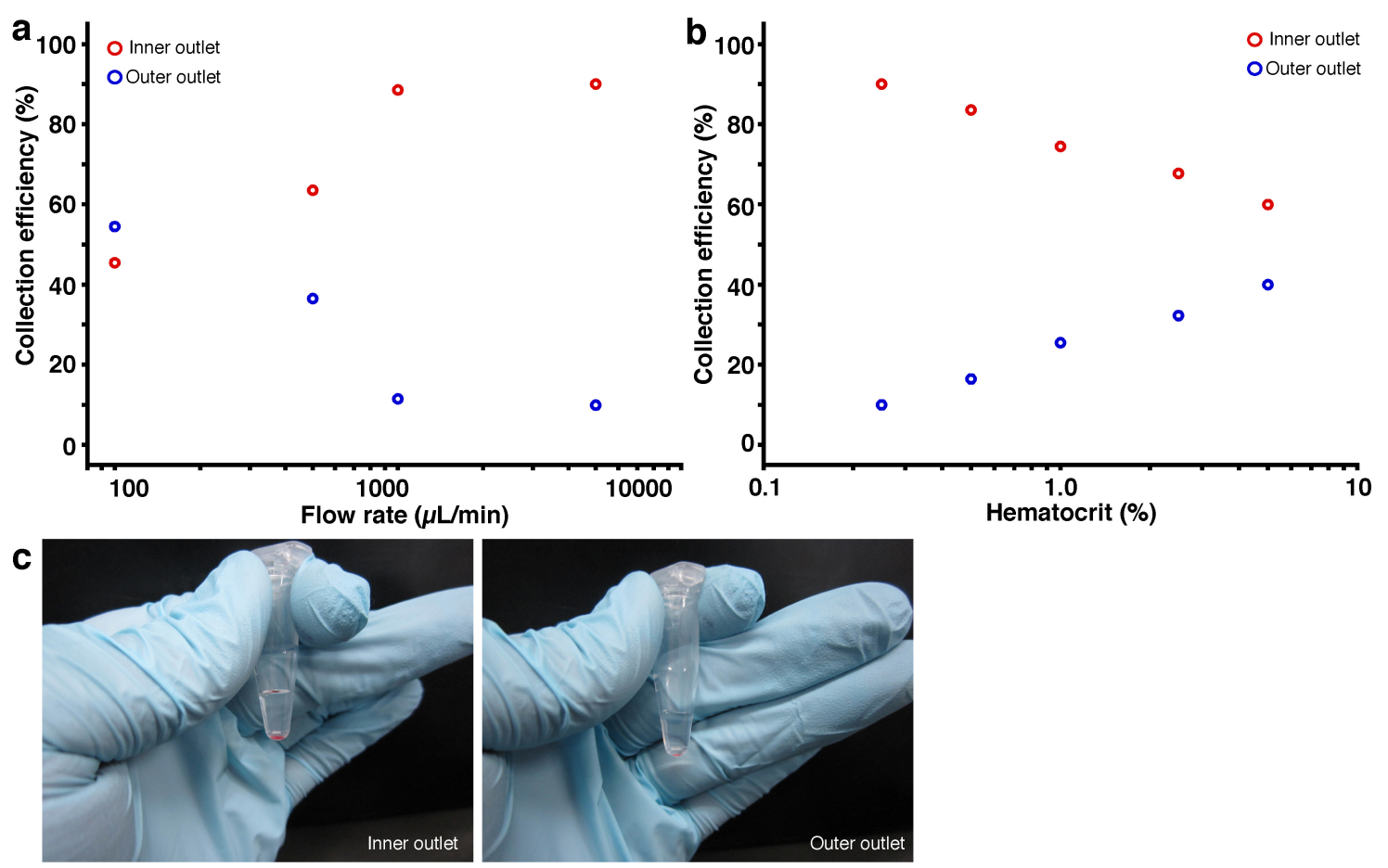

Figure 3. Collection efficiency of whole human blood cells. Cross-sectional area was $50,000 \mu \mathrm{m}^{2}$, the aspect ratio was 0.1 , and the number of microchannel spirals was 7.5. (a) Collection efficiency vs. flow rate. Initial hematocrit of blood samples was $0.25 \%$; (b) Collection efficiency vs. whole blood concentration. Flow rate was $5000 \mu \mathrm{m} / \mathrm{min}$; (c) Photographs of collected samples from inner and outer outlets after centrifugation. Flow rate was $5000 \mu \mathrm{m} / \mathrm{min}$, and initial hematocrit of blood samples was $0.25 \%$. Hemolyzed blood was not observed.

In summary, we have demonstrated a strategy for the preparation of autologous serum eye-drops based on spiral microchannels, which enables passive blood cell removal. The spiral microchannels achieved complete removal of $10 \mu \mathrm{m}$ microbeads as a model sample, and $90 \%$ removal of whole human blood cells. While the current removal efficiency is not yet enough to make autologous serum eye drops, flow rates with more than $10,000 \mu \mathrm{L} / \mathrm{min}$ (up to a flow rate without hemolysis), which can increase the inertial lift force, and lower aspect ratio microchannels (down to an aspect ratio without clogging) over eight spirals, which can decrease the Dean drag force, have the potential for application in preparation devices for blood cell removal, with the eventual goal of realizing the dry eye treatment. Since the present strategy allows researchers to make a further integration with a separation microchannel for platelets and clotting factors and a dilution microchannel, such microfluidic devices can offer a new path for the development of a one-step preparation system for autologous serum eye-drops.

Acknowledgments: This research was supported by the JSPS Grant-in-Aid for Scientific Research (A) 16H02091, Nanotechnology Platform Program (Molecule and Material Synthesis) of the Ministry of Education, Culture, Sports, Science and Technology (MEXT), and PRESTO, JST.

Conflicts of Interest: The authors declare no competing financial interests.

\section{References}

1. Noda-Tsuruya, T.; Asano-Kato, N.; Toda, I.; Tsubota, K. Autologous serum eye drops for dry eye after LASIK. J. Refract. Surg. 2006, 22, 61-66. [PubMed]

2. Ubels, J.L.; Foley, K.M.; Rismondo, V. Retinol secretion by the lacrimal gland. Investig. Ophthalmol. Vis. Sci. 1986, 27, 1261-1268. 
3. Ohashi, Y.; Motokura, M.; Kinoshita, Y.; Mano, T.; Watanabe, H.; Kinoshita, S.; Manabe, R.; Oshiden, K.; Yanaihara, C. Presence of epidermal growth factor in human tears. Investig. Ophthalmol. Vis. Sci. 1989, 30, 1879-1882.

4. Tsubota, K. New approaches in dry eye management: Supplying missing tear components to the ocular surface epithelium. In Current Opinions in the Kyoto Cornea Club; Kugler Publications: Amsterdam, The Netherlands, 1997; Volume 1, pp. 27-32.

5. Sackmann, E.K.; Fulton, A.L.; Beebe, D.J. The present and future role of microfluidics in biomedical research. Nature 2014, 507, 181-189. [CrossRef] [PubMed]

6. Tripathi, S.; Kumar, Y.V.B.V.; Prabhakar, A.; Joshi, S.S.; Agrawal, A. Passive blood plasma separation at the microscale: A review of design principles and microdevices. J. Micromech. Microeng. 2015, 25, 083001. [CrossRef]

7. Yang, S.; Undar, A.; Zahn, J.D. A microfluidic device for continuous, real time blood plasma separation. Lab Chip 2006, 6, 871-880. [CrossRef] [PubMed]

8. Jaggi, R.D.; Sandoz, R.; Effenhauser, C.S. Microfluidic depletion of red blood cells from whole blood in high-aspect-ratio microchannels. Microfluid. Nanofluid. 2007, 3, 47-53. [CrossRef]

9. Faivre, M.; Abkarian, M.; Bickraj, K.; Stone, H.A. Geometrical focusing of cells in a microfluidic device: An approach to separate blood plasma. Biorheology 2006, 43, 147-159. [PubMed]

10. Sollier, E.; Cubizolles, M.; Fouillet, Y.; Achard, J.L. Fast and continuous plasma extraction from whole human blood based on expanding cell-free layer devices. Biomed. Microdevices 2010, 12, 485-497. [CrossRef] [PubMed]

11. Marchalot, J.; Fouillet, Y.; Achard, J.L. Multi-step microfluidic system for blood plasma separation: Architecture and separation efficiency. Microfluid. Nanofluid. 2014, 17, 167-180. [CrossRef]

12. Rodriguez-Villarreal, A.I.; Arundell, M.; Carmona, M.; Samitier, J. High flow rate microfluidic device for blood plasma separation using a range of temperatures. Lab Chip 2010, 10, 211-219. [CrossRef] [PubMed]

13. Kersaudy-Kerhoas, M.; Kavanagh, D.M.; Dhariwal, R.S.; Campbell, C.J.; Desmulliez, M.P.Y. Validation of a blood plasma separation system by biomarker detection. Lab Chip 2010, 10, 1587-1595. [CrossRef] [PubMed]

14. Tripathi, S.; Prabhakar, A.; Kumar, N.; Singh, S.G.; Agrawal, A. Blood plasma separation in elevated dimension T-shaped microchannel. Biomed. Microdevices 2013, 15, 415-425. [CrossRef] [PubMed]

15. Prabhakar, A.; Kumar, Y.V.B.V.; Tripathi, S.; Agrawal, A. A novel, compact and efficient microchannel arrangement with multiple hydrodynamic effects for blood plasma separation. Microfluid. Nanofluid. 2015, 18, 995-1006. [CrossRef]

16. Lee, M.G.; Choi, S.; Kim, H.J.; Lim, H.K.; Kim, J.H.; Huh, N.; Park, J.K. Inertial blood plasma separation in a contraction-expansion array microchannel. Appl. Phys. Lett. 2011, 98, 253702. [CrossRef]

17. Xiang, N.; Ni, Z.H. High-throughput blood cell focusing and plasma isolation using spiral inertial microfluidic devices. Biomed. Microdevices 2015, 17, 110. [CrossRef] [PubMed]

18. Sun, M.; Khan, Z.S.; Vanapalli, S.A. Blood plasma separation in a long two-phase plug flowing through disposable tubing. Lab Chip 2012, 12, 5225-5230. [CrossRef] [PubMed]

19. Zhang, X.B.; Wu, Z.Q.; Wang, K.; Zhu, J.; Xu, J.J.; Xia, X.H.; Chen, H.Y. Gravitational sedimentation induced blood de lamination for continuous plasma separation on a microfluidics chip. Anal. Chem. 2012, 84, 3780-3786. [CrossRef] [PubMed]

20. Tachi, T.; Kaji, N.; Tokeshi, M.; Baba, Y. Simultaneous separation, metering, and dilution of plasma from human whole blood in a microfluidic system. Anal. Chem. 2009, 81, 3194-3198. [CrossRef] [PubMed]

21. Dimov, I.K.; Basabe-Desmonts, L.; Garcia-Cordero, J.L.; Ross, B.M.; Ricco, A.J.; Lee, L.P. Stand-alone self-powered integrated microfluidic blood analysis system (SIMBAS). Lab Chip 2011, 11, 845-850. [CrossRef] [PubMed]

22. Li, C.Y.; Liu, C.; Xu, Z.; Li, J.M. Extraction of plasma from whole blood using a deposited microbead plug (DMBP) in a capillary-driven microfluidic device. Biomed. Microdevices 2012, 14, 565-572. [CrossRef] [PubMed]

23. Moorthy, J.; Beebe, D.J. In situ fabricated porous filters for microsystems. Lab Chip 2003, 3, 62-66. [CrossRef] [PubMed]

24. Thorslund, S.; Klett, O.; Nikolajeff, F.; Markides, K.; Bergquist, J. A hybrid poly(dimethylsiloxane) microsystem for on-chip whole blood filtration optimized for steroid screening. Biomed. Microdevices 2006, 8, 73-79. [CrossRef] [PubMed] 
25. Wang, S.Q.; Sarenac, D.; Chen, M.H.; Huang, S.H.; Giguel, F.F.; Kuritzkes, D.R.; Demirci, U. Simple filter microchip for rapid separation of plasma and viruses from whole blood. Int. J. Nanomed. 2012, 7, 5019-5028.

26. Chung, K.H.; Choi, Y.H.; Yang, J.H.; Park, C.W.; Kim, W.J.; Ah, C.S.; Sung, G.Y. Magnetically-actuated blood filter unit attachable to pre-made biochips. Lab Chip 2012, 12, 3272-3276. [CrossRef] [PubMed]

27. Aran, K.; Fok, A.; Sasso, L.A.; Kamdar, N.; Guan, Y.L.; Sun, Q.; Undar, A.; Zahn, J.D. Microfiltration platform for continuous blood plasma protein extraction from whole blood during cardiac surgery. Lab Chip 2011, 11, 2858-2868. [CrossRef] [PubMed]

28. Crowley, T.A.; Pizziconi, V. Isolation of plasma from whole blood using planar microfilters for lab-on-a-chip applications. Lab Chip 2005, 5, 922-929. [CrossRef] [PubMed]

29. VanDelinder, V.; Groisman, A. Separation of plasma from whole human blood in a continuous cross-flow in a molded microfluidic device. Anal. Chem. 2006, 78, 3765-3771. [CrossRef] [PubMed]

30. Chen, X.; Cui, D.F.; Liu, C.C.; Li, H. Microfluidic chip for blood cell separation and collection based on crossflow filtration. Sens. Actuators B Chem. 2008, 130, 216-221. [CrossRef]

31. Kim, Y.C.; Kim, S.H.; Kim, D.; Park, S.J.; Park, J.K. Plasma extraction in a capillary-driven microfluidic device using surfactant-added poly(dimethylsiloxane). Sens. Actuators B Chem. 2010, 145, 861-868. [CrossRef]

32. Geng, Z.X.; Ju, Y.R.; Wang, Q.F.; Wang, W.; Li, Z.H. Multi-component continuous separation chip composed of micropillar arrays in a split-level spiral channel. RSC Adv. 2013, 3, 14798-14806. [CrossRef]

33. Kang, T.G.; Yoon, Y.J.; Ji, H.M.; Lim, P.Y.; Chen, Y. A continuous flow micro filtration device for plasma/blood separation using submicron vertical pillar gap structures. J. Micromech. Microeng. 2014, 24, 087001. [CrossRef]

34. Di Carlo, D. Inertial microfluidics. Lab Chip 2009, 9, 3038-3046. [CrossRef] [PubMed]

35. Ho, B.P.; Leal, L.G. Inertial migration of rigid spheres in 2-Dimensional unidirectional flows. J. Fluid Mech. 1974, 65, 365-400. [CrossRef]

36. Matas, J.P.; Morris, J.F.; Guazzelli, E. Inertial migration of rigid spherical particles in Poiseuille flow. J. Fluid Mech. 2004, 515, 171-195. [CrossRef]

37. Berger, S.A.; Talbot, L.; Yao, L.S. Flow in curved pipes. Annu. Rev. Fluid Mech. 1983, 15, 461-512. [CrossRef]

38. Di Carlo, D.; Irimia, D.; Tompkins, R.G.; Toner, M. Continuous inertial focusing, ordering, and separation of particles in microchannels. Proc. Natl. Acad. Sci. USA 2007, 104, 18892-18897. [CrossRef] [PubMed]

39. Di Carlo, D.; Edd, J.F.; Irimia, D.; Tompkins, R.G.; Toner, M. Equilibrium separation and filtration of particles using differential inertial focusing. Anal. Chem. 2008, 80, 2204-2211. [CrossRef] [PubMed]

40. Gossett, D.R.; Di Carlo, D. Particle focusing mechanisms in curving confined flows. Anal. Chem. 2009, 81, 8459-8465. [CrossRef] [PubMed]

41. Di Carlo, D.; Edd, J.F.; Humphry, K.J.; Stone, H.A.; Toner, M. Particle segregation and dynamics in confined flows. Phys. Rev. Lett. 2009, 102, 094503. [CrossRef] [PubMed]

42. Kuntaegowdanahalli, S.S.; Bhagat, A.A.; Kumar, G.; Papautsky, I. Inertial microfluidics for continuous particle separation in spiral microchannels. Lab Chip 2009, 9, 2973-2980. [CrossRef] [PubMed]

43. Asmolov, E.S. The inertial lift on a spherical particle in a plane Poiseuille flow at large channel Reynolds number. J. Fluid Mech. 1999, 381, 63-87. [CrossRef]

44. Schonberg, J.A.; Hinch, E.J. Inertial migration of a sphere in poiseuille flow. J. Fluid Mech. 1989, $203,517-524$. [CrossRef]

(C) 2016 by the authors; licensee MDPI, Basel, Switzerland. This article is an open access article distributed under the terms and conditions of the Creative Commons Attribution (CC-BY) license (http://creativecommons.org/licenses/by/4.0/). 